\title{
Mathematical modeling of heat and mass exchange processes in the evaporative cooler
}

\author{
Nizomjon Usmonov ${ }^{1 *}$, Shaxlo Mavjudova ${ }^{1}$, and Adeliya Ivanisova ${ }^{1}$ \\ ${ }^{1}$ Department of Thermodynamics, Tashkent State Technical University, 100097 Tashkent, \\ Uzbekistan
}

\begin{abstract}
This article describes the advantages of the widespread using of the evaporative coolers for cooling recycled wastewater in the air conditioning systems in various industries. The mathematical model of heat and mass transfer processes in the evaporative coolers has been developed. The dependence of the changes in the temperature of the air leaving the evaporator on the irrigation density is considered. When comparing the values obtained by using mathematical expressions and experiments, the resulting difference was $6.7 \%$.
\end{abstract}

\section{Introduction}

Today, great attention is being paid to one of the country's most important economic sectors - the construction of technological equipment for the energy industry, which takes into account modern requirements, such as air conditioning and cooling systems [1, 2]. Energy efficiency is a key component of Uzbekistan's 2017-2021 Strategic Action Plan, which emphasizes reducing energy and resource consumption in the economy through widespread adoption of energy-saving technologies in production. According to the regulations, the purpose of this study is to help fulfill those requirements to a certain extent.

While the cost of electrical energy for air conditioning of buildings has increased significantly, the development of highly efficient cooling systems has become urgent [3] at the production facilities of the republic.

In hot and dry summer seasons in Uzbekistan to bring the parameters of the air in the room to comfortable, it is the necessary to use the normalization of the microclimate. When it comes to passenger transportation, cooling and humidifying the air in the working and living areas is of special relevance. In this case, the optimal cooling of the air relative to the environment is $6 \div 10$ with a relative humidity of $40-60 \%$.

Furthermore, some businesses have very strict criteria for the air temperature in rooms where technological activities are performed, for cooling raw materials, intermediate materials, or the end product, and for a relatively high level of humidity (40-50 percent ).

For certain reasons in the republic most common coolers (air conditioners) compression type, including a split system, which on the one hand consume a lot of power and create an overload to the electrical network in the summer months, and on the other hand, further dry

*Corresponding author: nizomiddin1981@mail.ru 
the air in the cooling room, causing various diseases of the respiratory tract and skin, a feeling of a painful state of the whole human body.

A significant reduction in electricity consumption for air cooling can be achieved using evaporative-type coolers, where the working substance is water, adiabatic evaporates in a stream of relatively dry air, and a decrease in air temperature is achieved due to the heat of its evaporation $[4,5,6]$. In this case, the enthalpy of the air-water system does not change. These chillers simultaneously humidify the cooled air supplied to the work area, which is both an advantage and a disadvantage.

Evaporative cooling in its simplest form (spraying or evaporating water from the surface of microporous ceramics) has been used since ancient times in different countries with hot and dry climates [7]. In this case, energy from external sources is required only to replenish the stock of evaporating water.

\section{Methods}

The following regulations apply to the materials of the irrigation layer in water and air coolers of this type:

- a continuous surface with the same filling capacity with the largest sweep;

- for energy supply, the most complete wetting of the surface or material with water at the lowest cost;

- evaporative cooling indicators with high efficiency and low aerodynamic resistance;

- material resistance to corrosion, weathering, the formation of harmful smells;

- resistance to bacterial infections;

- cheap costs and a large supply of raw resources [8].

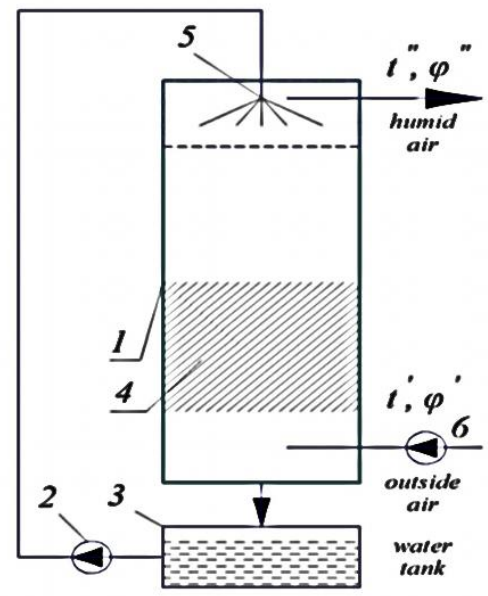

Fig. 1. Evaporative cooler with watered layers, based on a fundamental calculation: 1 - evaporative cooler, 2 - circulation (water) pump, 3 - sump, 4 - Rashig ring's nozzle, 5 - nozzle, 6 - air fan, $t$ and $\varphi$ - air temperature and air humidity, $t_{w}$ - irrigation water temperature ('- means at the inlet and "- at the outlet of the irrigation chamber) $[8,9]$.

The irrigated layers are filled with synthetic fibers, wood fibers and shavings, fiberglass, palm tree bark fibers, metal wires, porous plastic plates, and thin metal sheets.

The paper analyzes evaporative cooling of water and conditioned air in irrigated layers, where the parameters of humid air are allowed to be identical to the equivalent indicators of saturated air at the irrigated water temperature $\left(t_{w}\right)$. Evaporative water coolers with irrigated layers that have lesser air capacity are located in the area, which implemented in 
the most serviced premises or in the immediate closeness of them, are more cost effective and convenient for the all types of buildings.

Fig. 1 depicts a basic calculation for an evaporative water and air cooler with irrigated layers [9].

Researching heat and mass transfer processes in the evaporative coolers, it is necessary to visualize the thermodynamic efficiency of the processes, and to determine the sources of losses in them. The process of evaporation of the recycled water in the evaporative coolers occurs in the conditions of interaction with the environment and the evaluation of the potential resources of the thermodynamic system "cooling recycled water - environment" should be made taking into account the influence of environmental parameters, first of all, such as temperature and relative humidity.

For the process of the water evaporation, as for any heat and mass transfer process, it is necessary to make at least two balances: material and heat. The first necessary condition in this case is the definition of the thermodynamic system's boundaries in the form of a balance surface (Fig. 2), which allows to estimate the direction and dimension of various flows [8, 9]. If the evaporative cooler of the recycled water is considered as a thermodynamic system, when the mass flow crosses its balance surface, i.e. with periodic or continuous heat and mass transfer between a given thermodynamic system and the environment, the thermodynamic system is considered open. By this definition, the evaporative coolers of the recycled water are open thermodynamic systems.

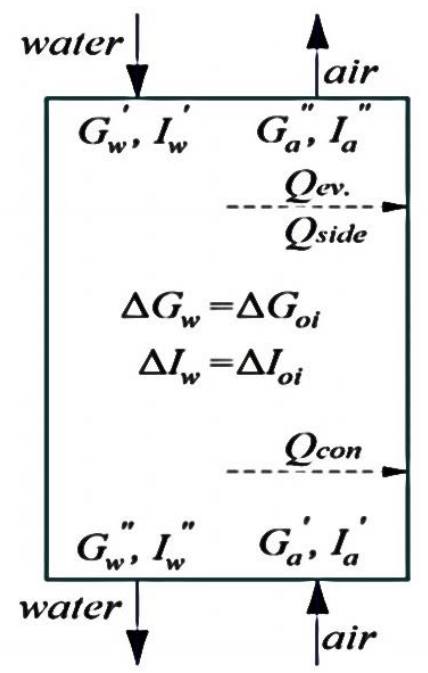

Fig. 2. A schematic view of the material (a) and heat balance (b) of the evaporative cooler: a) $G_{w}^{\prime}$ and $G_{w}^{\prime \prime}$ - the flows of cooled (at the inlet) and (at the outlet) circulating water in the evaporative cooler, $G_{a}^{\prime}$ и $G_{a}^{\prime \prime}$ - the flows of humid air at the inlet to the evaporative cooler and at the outlet it, $\Delta G_{o i}$ - the flow of moisture (water vapor) passing from the cooled water to the humid air; b) $I_{w}^{\prime}$ и $I_{w}^{\prime \prime}$ - the enthalpy of cooled (at the inlet) and (at the outlet) circulating water in the evaporative cooler, $I_{a}^{\prime}$ и $I_{a}^{\prime \prime}$ - the enthalpy of humid air at the inlet and at the outlet of the evaporative cooler, $Q_{e v}$ и $Q_{c o n}$ - the heat flows, passing from the cooled water to the humid air by evaporation and convective heat exchange, $Q_{\text {side }}$ - the heat flow through the side wall of the cooler [9].

\section{Results and Discussion}

The form of the differential equation of the studied water-air cooler stationary heatbalance, according to the fundamental design concept depicted in Fig. 1:

where

$$
d Q_{w}=d Q_{c o n}+d Q_{e v}
$$




$$
d Q_{w}=G_{w} * C p_{w} * d t_{w}
$$

$d Q_{w}$ - the heat flow given off by the cooled water;

$$
d Q_{\text {con }}=\alpha_{\text {con }} *\left(t_{a}-t_{w}\right) * d F_{i . l}
$$

$d Q_{c o n}$ - the sensible (convective) heat flow from the humid air to water;

$$
d Q_{e v}=\beta_{P} * r *\left(P_{\text {sur }}-P_{0}\right) * d F_{i . l .}
$$

$d Q_{e v}$ - the latent (by evaporation) heat flow from water to humid air;

$\alpha_{c o n}$ - the coefficient of convective heat exchange in the irrigated layer between humid air and water; $\beta_{P}$ - coefficient of mass exchange in the irrigated layer between water and humid air, referred to the difference in partial pressures on the evaporation surface $\left(P_{\text {sur }}\right)$ and $\left(P_{0}\right) ; r$ - a latent heat of vaporization of water;

$$
d F_{i . l .}=a * d V=a * F_{i . c h} d \delta
$$

$d F_{i . l .}$ - the heat and mass exchange surfaces of the irrigated layer in its elementary volume $d V$

$F_{i . c h}$ - the surface area of the cross-section irrigation chamber;

$\delta-$ the thickness of irrigated layer.

Substituting (2) - (5) into (1), we obtain [8]

$$
\frac{G_{w_{i . c h} .}}{a} * C p_{w} * d t_{w}=\left[\alpha_{c o n} *\left(t_{a}-t_{w}\right)-\beta_{P} * r *\left(P_{\text {sur }}-P_{0}\right)\right] d \delta
$$

where

$$
G_{w_{i . c h .}}=\frac{G_{w}}{F_{i . c h}}
$$

$G_{w_{i . c h}}$ - the irrigation water flow's density, per unit area of the cross-section of the irrigation chamber.

To solve the equation (6), initially, the temperature of humid air by a dry bulb $t_{a}$ through the temperature of humid air by a wet bulb $t_{w e t}$. should be calculated. In order to carry out this, the conditions of the established thermodynamic equilibrium between the obvious and latent heat will be utilized.

which were proposed in [8].

$$
\alpha_{\mathrm{con}} *\left(t_{a}-t_{w e t}\right)=\beta_{P} * r *\left(P_{t_{w e t}}-P_{0}\right)
$$

In (8) $P_{t_{w e t}}$ is the partial pressure of water vapor over the surface of the evaporated water, which has the saturation temperature, that is, the wet thermometer.

Determine the value of $t_{a}$ from (8)

Substituting (9) into (6), we obtain

$$
t_{a}=t_{w e t}+\frac{\beta_{P} * r}{\alpha_{c o n}} *\left(P_{t_{w e t}}-P_{0}\right)
$$

$$
\begin{aligned}
& \quad \frac{G_{w_{i . c h .}} * C p_{w} * d t_{w}}{a}+\beta_{P} * r *\left(P_{t_{w e t}}-P_{0}\right)-\alpha_{c o n} * t_{w}-\beta_{P} * r \\
& =\left[\alpha_{c o n} * t_{w e t}+\beta_{P} *\left(P_{\text {sur }}-P_{0}\right)\right] d \delta
\end{aligned}
$$

or

$$
\frac{G_{w_{i . c h} .}}{a} * C p_{w} * d t_{w}=\left[\alpha_{c o n} *\left(t_{w e t}-t_{w}\right)+\beta_{P} * r *\left(P_{t_{w e t}}-P_{0}\right)\right]
$$

To solve the equation (10) concerning to the desired temperature $t_{w}$, based on the dependence of the elasticity of the saturated vapor over the water, according to the established by approximation dependence between $P_{t_{w e t}}$ and $t_{w e t}$, and $P_{\text {sur }}$ and $t_{w}$. As the calculations for this dependence shows, in the range of change $t_{w e t}$ from 10 to 25 , the approximations of $P_{t_{w e t}}$ and $P_{\text {sur }}$ through $t_{w e t}$ and $t_{w}$ can be presented in the following form [8]

$$
\begin{aligned}
& P_{t_{w e t}}=t_{w e t}-1,5^{\circ} \mathrm{C} \\
& P_{\text {sur }}=t_{w}-1,5^{\circ} \mathrm{C}
\end{aligned}
$$

Substituting (11) and (12) into (10), we obtain 
from where

$$
G_{w_{i . c h .}} * C p_{w} * d t_{w}=-\left(\alpha_{c o n}+\beta_{P} * r\right) *\left(t_{w}-t_{w e t}\right) * a * d \delta
$$

$$
\frac{d t_{w}}{t_{w}-t_{w e t}}=e^{-\frac{\left(\alpha_{c o n}+\beta_{P^{*}}\right) * a * d \delta}{G_{w_{i . c h .}}{ }^{* C p_{w}}}}
$$

After Integrating the left side of (13) from $t_{w}^{\prime}$ and $t_{w}^{\prime \prime}$, and the right side from 0 to $\delta$, we obtain

or

$$
\frac{t_{w}^{\prime \prime}-t_{w e t}}{t_{w}^{\prime}-t_{w e t}}=e^{-\frac{\left(\alpha_{c o n}+\beta_{P} * r\right) * a * \delta}{G_{w_{i . c h .}}{ }^{* C p_{w}}}}
$$

$$
t_{w}^{\prime \prime}=t_{w e t}+\left(t_{w}^{\prime}-t_{w e t}\right) * e^{-\frac{\left(\alpha_{c o n}+\beta_{P} * r\right) * a * d \delta}{G_{w_{i . c h .}}{ }^{* C p_{w}}}}
$$

As follows from the analysis of the solution (14), at $\left(\alpha_{c o n}+\beta_{P} * r\right) * a * \delta \ll G_{w_{i . c h} .} *$ $C p_{w}$, i.e. for huge values of the specific consumption of cooling water at a small thickness of irrigated layer $(\delta) t_{w}^{\prime \prime} \rightarrow t_{w}^{\prime}$, and conversely, $\left(\alpha_{c o n}+\beta_{P} * r\right) * a * \delta \gg G_{w_{i . c h} .} * C p_{w}$, there will be $t_{w}^{\prime \prime} \leftarrow t_{w}^{\prime}$.

To determine the value of $t_{w}^{\prime \prime}$, as follows from (14), all other things being equal (meaning, to find $t_{w}^{\prime}, G_{w_{i . c h}}, t_{w e t}$ and $\delta$, it is required to determine the values of $\alpha_{c o n}$ and $\beta_{P}$ ) [9].

According to the experimentally obtained results (Kokorin) [7] when the value of the irrigation coefficient changes

$$
\mu=\frac{G_{w_{\text {spec }}}}{G_{a_{\text {spec }}}}
$$

from 0.015 to $0,15 \frac{\mathrm{kg} \text { water }}{\mathrm{kg} \text { air }}$ the values of $\alpha_{\text {con }}$ and $\beta_{P}$ for the irrigated layer of fiberglass with the diameter of $0.135 \mathrm{~mm}$, the length of $200 \mathrm{~mm}$ and $a=\frac{F_{i . l .}}{V}=29629 \frac{1}{\mathrm{~m}}$ can be used the values, respectively $\alpha_{\text {con }}=58,15 \frac{\mathrm{W}}{\mathrm{m}^{2} *^{\circ} \mathrm{C}}$ and $\beta_{P} * r=120 \frac{\mathrm{kg}}{\mathrm{m}^{2} * \text { hour } * a t}$ [8].

Considering that the value of the specific consumption of humid air through the irrigated layer $G_{a_{\text {spec }}}$ in (15) is connected with the linear speed of the humid air flow $\left(\vartheta_{a}\right)$ according to the expression, $t_{w}^{\prime \prime}$, then the solution (14) can be presented in the form [9]

$$
t_{w}^{\prime \prime}=t_{w e t}+\left(t_{w}^{\prime}-t_{w e t}\right) * e^{-\frac{\left(\alpha_{c o n}+\beta_{P} * r\right) * a * \delta}{\mu * a^{*} \rho_{a} C p_{w}}}
$$

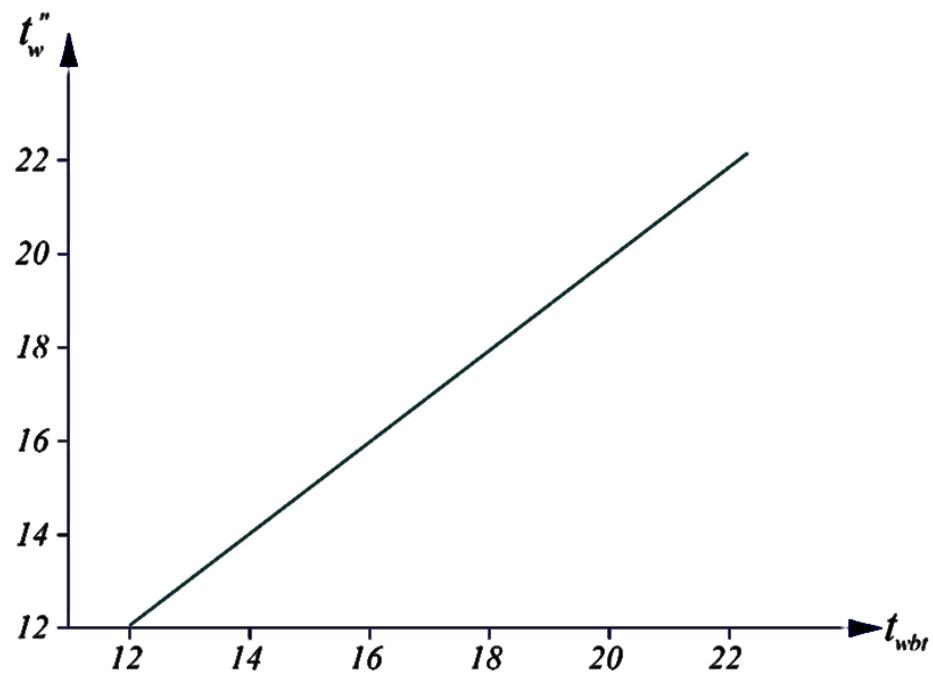

Fig. 3. The relationship between the final water temperature of the circulating water evaporative cooler and the temperature of the wet thermometer air humidity 
According to the results of the calculations performed, by definition $t_{w}^{\prime \prime}$ by using the formula (16) at $\alpha_{\text {con }}=58,15 \frac{W}{m^{2} *^{\circ} \mathrm{C}}, \quad \beta_{P} * r=120 \frac{\mathrm{kg}}{\mathrm{m}^{2} * \text { hour } * a t}, \quad a=16000 \frac{\mathrm{m}^{2}}{\mathrm{~m}^{3}}, \quad \delta=$ $0,002 \mathrm{~m}, \mu=0,1, \vartheta_{a}=2 \mathrm{~m} / \mathrm{s}, \rho_{a}=1,25 \mathrm{~kg} / \mathrm{m}^{3}$ and $\mathrm{Cp}_{a}=4186,8 \frac{\mathrm{J}}{\mathrm{kg} *{ }^{\circ} \mathrm{C}}$ the value of $t_{w}^{\prime \prime}$ at $t_{w}^{\prime}=25^{\circ} \mathrm{C}$ and $t_{w e t}=18^{\circ} \mathrm{C}$ is formed $t_{w}^{\prime \prime}=18+(25-18) * \mathrm{e}^{\frac{-(58+120) * 16000 * 0,002}{0,1 * 2,0 * 1,25 * 4186,8}}=$ $18+7 * \mathrm{e}^{-2,0407}=18,91^{\circ} \mathrm{C}$.

The value of the thermal efficiency of the evaporative water cooler, which were determined in concerning to the $E=\frac{t_{w}^{\prime}-t_{w}^{\prime \prime}}{t_{w}^{\prime}-t_{w e t}}$ in this case is

$$
E=\frac{t_{w}^{\prime}-t_{w}^{\prime \prime}}{t_{w}^{\prime}-t_{w e t}}=\frac{25-18,91}{25-18,0}=0,87
$$

and has a little effect on the values of the heat and mass exchange coefficients, which is described by the complete wettability of the irrigated layer material, even when the irrigation density has the low values $\left(G_{w_{\text {spec }}}\right)$.

\section{Conclusions}

The values of $t_{w}^{\prime}$ и $t_{w}^{\prime \prime}$ in (16), can be defined from the calculation of expressions obtained on the basis of the thermal modeling of circulating water cooling process in the evaporative cooler of the type considered. At present, the parameters of individual units are being optimized, the relationship between the degree of cooling and the humidity of the cooled air and its speed, humidity and temperature of the outside air is being investigated.

Thus, the proposed scheme of evaporative cooling of buildings provides stable cooling of premises and allows, in comparison with compression air conditioners, to reduce power consumption by $8-9$ times.

\section{References}

1. A. Anarbaev, R. Zakhidov, O. Tursunov, D. Kodirov, U. Vakhidov, U. Khaliknazarov, Z. Yusupov, A. Kushev, Using of evaporative cooling systems in poultry farms, IOP Conf. Ser.: Earth Environ. Sci. 614, 012015 (2020)

2. A. Anarbaev, O. Tursunov, R. Zakhidov, D. Kodirov, U. Vakhidov, E. Bozorov, G. Tuhtaeva, A. Babaev, Determination the installation efficiency of the evaporative air cooling in the greenhouse by temperature-moisture regime, IOP Conf. Ser.: Earth Environ. Sci. 614, 012026 (2020)

3. K. Lundgren-Kownacki, E. D. Hornyanszky, T. A. Chu, J. A. Olsson, P. Becker, Challenges of using air conditioning in an increasingly hot climate, International journal of biometeorology, 62(3), 401-412 (2018)

4. A. F. Santos, P. D. Gaspar, H. J. L. Souza, Measuring the Energy Efficiency of Evaporative Systems through a New Index-EvaCOP, Energies 14, 2689 (2021)

5. A. Lal Basediya, D. V. Samuel, V. Beera, Evaporative cooling system for storage of fruits and vegetables - a review, Journal of food science and technology, 50(3), 429442 (2013)

6. P. Glanville, A. Kozlov, V. Maisotsenko, Dew point evaporative cooling: Technology review and fundamentals, ASHRAE Transactions 117, 111-118 (2011)

7. R. Boukhanouf, H. G. Ibrahim, A. Alharbi, and M. Kanzari, Investigation of an Evaporative Cooler for Buildings in Hot and Dry Climates, Journal of Clean Energy Technologies 2(3), 221-225 (2014) 
8. N. O. Usmonov, Sh. S. Sanayev, Z. E. Yusupov, Calculation of temperature of routine water cooled in irrigated layers, Technical Science and Innovation, 2, 249-256 (2019)

9. N. O. Usmonov, Kh. S. Isakhodzhayev, M. A. Koroli, Determining the parameters of the fluid layer with a rigid mobile nozzle, Thermal Engineering 68(3), 221-227 (2021) 